\title{
Assessment of Dental Emerge Base on Age in Sundanese People Using Panoramic Radiograph
}

\author{
Yetty Herdiyati Nonong ${ }^{1}$, Lusi Epsilawati ${ }^{2}$ \\ ${ }^{1}$ Pedodontic Dentistry and ${ }^{2}$ Dentomaxilofacial Radiology, Faculty of Dentistry, Padjadjaran University, Bandung, West Java, Indonesia
}

\begin{abstract}
Background: Growth and development of the teeth are very influential on a chronological age. There are many techniques to determine the chronological age of a person to analyze it from the dental emerges. Merge teeth or tooth eruption is based on a lot of things that affect no age, sex, race, location stay/ life and other. The aim of this study is to analyze the relationship emerge tooth for age and gender in Sundanese People Using Panoramic Radiograph. Materials and Methods: This study used a method description with technical survey, conducted in the all the teeth in the jaw. The population is all of the data radiographs that were aged 7-12 years. Data is obtained by observing the emerge of the entire tooth in jaw associated with age. The data is then processed and displayed in the form of tables and graphs. Results: Based on the results shown there are differences in dental Emerge different picture from every different age groups, and the increasing age, the dental emerge differently. Conclusion: Growth and development of the first and second premolars using panoramic radiographs may help determine the age of a person.
\end{abstract}

Keywords: development, emerge, teeth, panoramic, Sundanese

\section{Introduction}

Emerge in the permanent dentition is an important stage in life and it depends on a person's gender and race ${ }^{1}$. Racial, ethnic, sexual, and individuals factors can influence the process of eruption and are usually taken into consideration in determining the standard of tooth eruption 2 and 3. The normal teeth will go through five stages, namely: preeruptive movements, intraosseous stage, mucosal penetration, preocclusal and postocclusal ${ }^{3}$. Tooth eruption is the final step in the process of tooth formation. Physiologically, the teeth will migrate from the bone of the jaw toward the oral cavity or emerge. At the end of this process, the tooth found a place where there should be and each individual case is different ${ }^{2}$. Typically, tooth eruption begins around the age of 6 months with the first molar tooth eruption and ends at the age of about 18-25 years old with 3rd molar tooth eruption. Tooth eruption and growth are associated with chronological age. Generally, each tooth has a specific order. Dental age criteria are widely used by dentists to determine the age kronlogis because it is relatively easier and individual variation is limited.

The aim of this study was to collect data on the age of the eruption (dental emerge) and variations to the teeth in the jaw or both upper and lower jaw.

\section{Materials and Method}

This study was a descriptive study in which the results were obtained in the form of quantitative data ${ }^{4}$. The population is all the panoramic radiographs of patients aged 7-12 years, with a total of 40 panoramic radiographs for every age group. The data was collected based on the presence or absence of the tooth in the mouth and radiographically, then the recording is done on all the 1-5 teeth both maxilla or mandible. The teeth are declared present and accounted for when they reach the top of the bone.
Figure 1: Erupted and unerupted teeth.

Panoramic Radiography photo used was taken with a digital x-ray type of Picasso Trio; EPX-Impla brand, type B applied part Impla, serial number 0165906; production Vatech \& Ewoo of Korea. Processor used to process data is a computer unit Axio with specifications Pentium 4, 4G memory. Software used is EasyDent 4 Viewer Program of Vatech \& Ewoo of Korea ${ }^{5}$.

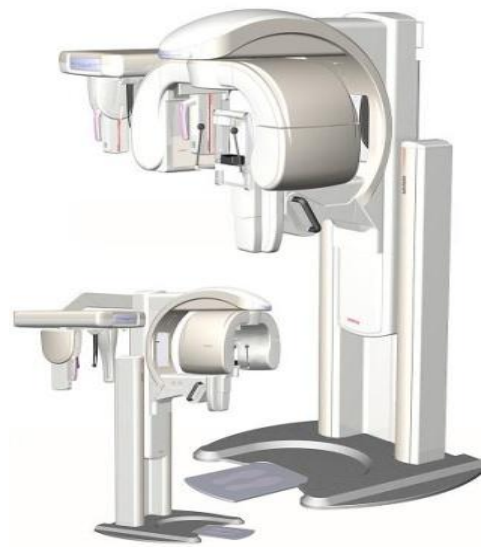

Figure 2: Plane type of X-ray type Picasso Trio; brand EpxImpla, type B appliedpart Impla, serial number 0165906; production of Vatech \& E-woo Korea ${ }^{5}$.

\section{Results}

Tooth emerging research data obtained by age is as follows:

Table 1: Emerge for Upper Jaw

\begin{tabular}{|c|c|c|c|c|c|}
\hline \multirow{2}{*}{ Age } & \multicolumn{5}{|c|}{ Tooth } \\
\cline { 2 - 6 } & $\begin{array}{c}\text { Sental } \\
\text { Incicive }\end{array}$ & $\begin{array}{c}\text { Lateral } \\
\text { Insisve }\end{array}$ & Canine & $\begin{array}{c}\text { First } \\
\text { Premolar }\end{array}$ & $\begin{array}{c}\text { Second } \\
\text { Premolar }\end{array}$ \\
\hline 7 & 24 & 30 & 40 & 40 & 40 \\
\hline 8 & 0 & 0 & 40 & 40 & 40 \\
\hline 9 & 0 & 0 & 40 & 13 & 13 \\
\hline 10 & 0 & 0 & 40 & 32 & 31 \\
\hline 11 & 0 & 0 & 30 & 30 & 25 \\
\hline 12 & 0 & 0 & 40 & 20 & 40 \\
\hline
\end{tabular}




\section{International Journal of Science and Research (IJSR) \\ ISSN (Online): 2319-7064 \\ Index Copernicus Value (2013): 6.14 | Impact Factor (2014): 5.611}

Table 2: Emerge for Lower Jaw

\begin{tabular}{|c|c|c|c|c|c|}
\hline \multirow{2}{*}{ Age } & \multicolumn{5}{|c|}{ Tooth } \\
\cline { 2 - 6 } & $\begin{array}{c}\text { Sental } \\
\text { Incicive }\end{array}$ & $\begin{array}{c}\text { Lateral } \\
\text { Insisve }\end{array}$ & Canine & $\begin{array}{c}\text { First } \\
\text { Premolar }\end{array}$ & $\begin{array}{c}\text { Second } \\
\text { Premolar }\end{array}$ \\
\hline 7 & 24 & 30 & 40 & 40 & 40 \\
\hline 8 & 0 & 0 & 40 & 40 & 40 \\
\hline 9 & 0 & 0 & 40 & 18 & 18 \\
\hline 10 & 0 & 0 & 15 & 19 & 40 \\
\hline 11 & 0 & 0 & 30 & 30 & 27 \\
\hline 12 & 0 & 0 & 40 & 25 & 39 \\
\hline
\end{tabular}

In graphic form:

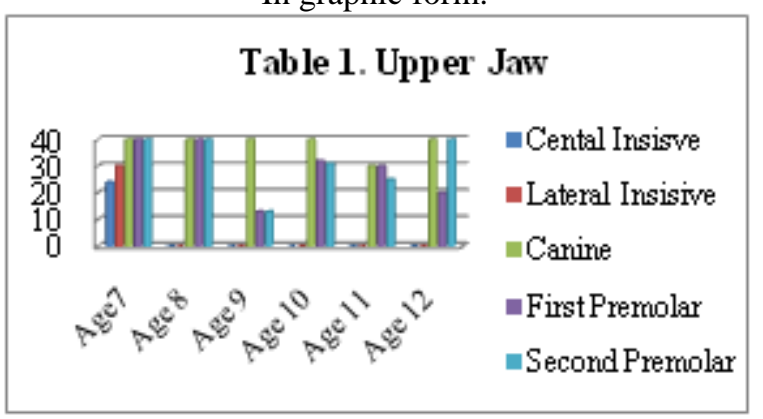

Table 2. Lower Jaw

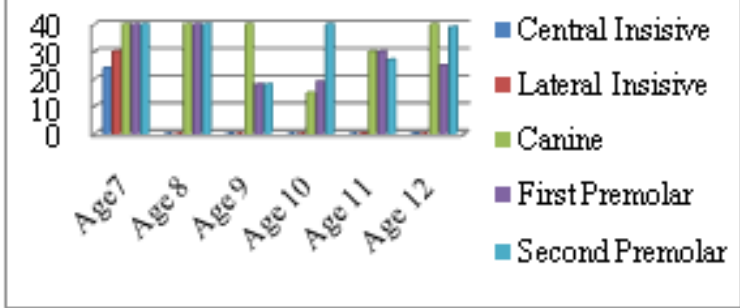

Results showed that at the age of 7 years old, from 40 samples, the teeth that have emerged are only central and lateral incisor teeth while the other teeth have not erupted. For age of 12 years old all the teeth have erupted.

\section{Discussion}

Growth and development of the teeth is very important to note either for treatment or for forensic purposes in order to determine a person's age. Tooth eruption is a biological process that runs continuously starting from the appearance of the teeth above the mucosa and into the oral cavity until contact with its contrary teeth ${ }^{6}$. Based on several studies, eruptions of the permanent teeth have order and age specific. Generally, the eruption of permanent teeth is found at the age of 5-13 years except the third molars appear at the age of 17 and 21 years ${ }^{7.8}$. Other studies say that there are variations in the eruption of teeth in each different race ${ }^{6,7,8}$.

This research shows that tooth eruption obviously correlates with a person's age and while sex factor shows no significant differences. Actually there are other factors that affect the eruption of teeth like genetics, hormonal factors, geographical location, ethnicity, gender, economic status and nutrition. These factors produce a major impact and cause differences in the time of eruption ${ }^{9.10}$.

Supposedly there is a difference between the time of the eruption of boys and girls. This is caused by differences in the level of maturation between boys and girls. Based on the studies that have been done, the woman showed the eruption faster than men because the maturation of bone is faster in girls compared to boys ${ }^{11.12}$. In this study it is not visible, allegedly because of the sample is too small. To see the relationship between chronological age and tooth eruption, other studies say there is no guarantee with age that the tooth will erupt. Growth, development, maturation until the time of eruption of each tooth is not interconnected ${ }^{13,14}$

\section{Conclusion}

The tooth eruption time amongst the is running in a certain sequence. There is a relationship between age and time of tooth eruption and no visible difference of the time of tooth eruption between men and women.

\section{References}

[1] Faizal C ,Peedikayil . 2011. DELAYED TOOTH ERUPTION. Publish Medic. Kannur Dental College and Hospital. Anjarakandy, Kerala, India. Received Nov 3,2011: Accepted Dec 19, 2011

[2] Pahkala R, Pahkala A, Laine T. 1991. Eruption pattern of permanent teeth in a rural community in northeastern Finland. Acta Odontol Scand. Vol : 49:341-9.

[3] Proffit WR, Fields HW. 2000. Contemporary orthodontics. 3 rd ed. Mosby Inc

[4] Sugiyono. Statistika Untuk Penelitian. 2003. Alphabetha. Bandung : 115,62-63

[5] , 2008. Current Product Picaso Trio. Disadur dari www. Vatech.com (diunduh Februari, 2013)

[6] Maria N1, Mihaela M 1, Cosntan A $\mathrm{M}_{2}$, Eduard C1, et All. 2011. Study Regarding the Sequencw of Eruption of Permanen of permanent Teeth at A Goup of Children of Children from Buzumidai Dinu Scatariu. ec iunea Genetic i Biologie Molecular. TOM XII.

[7] Arvind Jain1, Vandana Jain.2015. The Study of Teeth eruption in Female Children of Malwa Region. International Archives of Integrated Medicine, Vol. 2

[8] Agarwal KN, Gupta R, Faridi MMA, Kalra N: Permanent dentition in Delhi boys of age 5-14. Indian Pediatr 2004, 41:1031-1035.

[9] Khan NB, Chohan AN, AlMograbi B, AlDeyab S, Zahid T, AlMoutairi M: Eruption time of permanent first molars and incisors among a sample of Saudi male schoolchildren. Saudi Dent J 2006, 18:18-24.

[10] Pahkala R, Pahkala A, Laine T: Eruption pattern of permanent teeth in a rural community in North Eastern Finland. Acta Odontol Scand 1991,49:341-349

[11] Lee MMC, Low WD, Chang SFS: Eruption of the permanent dentition of Southern Chinese children in Hong Kong. Arch Oral Biol 1965, 10:849-861.

[12] Triratana T, Hemindra, Kiatiparjuk C: Eruption of permanent teeth in malnourished children. J Dent Assoc Thai 1990, 40:100-108.

[13] Khan N: Eruption time of permanent teeth in Pakistani children. Iranian J Publ Health 2011, 40:63-73.

[14] Kaur B, Singh R: Physical growth and age at eruption of deciduous and permanent teeth in well nourished Indian girls from birth to twenty years. Am J Hum Biol 1992, 4:757-766. 


\section{International Journal of Science and Research (IJSR) \\ ISSN (Online): 2319-7064}

Index Copernicus Value (2013): 6.14 | Impact Factor (2014): 5.611

\section{Author Profile}

Yetty Herdiyati Nonong (Indonesia) received DDS from Universitas Padjadjaran in 1979. She continued to specialist program in Pedodontics in Universitas Padjadjaran and graduated in 1995. She finished her doctorate degree from Universitas Padjadjaran in 2007. She is a lecturer in Pedodontics Department of Universitas Padjadjaran. She is also a member of Indonesian Dentist Association and Indonesian Pediatric Dentist Association.

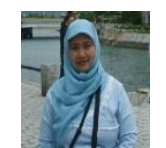

Lusi Epsilawati (Indonesia) received DDS from Universitas Padjadjaran in 2003. She continued to master program in health $\mathrm{s}$ in Universitas Padjadjaran in 2012. She's currently a lecturer in Radiology and

Maxillofacial Department of Universitas Padjadjaran. 